\title{
Phenotypic and genotypic differences between Indian and Scandinavian women with gestational diabetes mellitus
}

\author{
Arora, G. P.
}

2019-08

Arora , G P , Åkerlund, M , Brons , C , Moen , G-H, Wasenius, N S , Sommer, C, Jenum , A K , Almgren , P , Thaman , R G , Orho-Melander , M , Eriksson , J , Qvigstad , E , Birkeland, K, Berntorp , K, Vaag , A A , Groop , L \& Prasad, R B 2019 , ' Phenotypic and genotypic differences between Indian and Scandinavian women with gestational diabetes mellitus ' , Journal of internal medicine , vol. 286 , no. 2 , pp. 192-206 . https://doi.org/10.1111/joim.12903

http://hdl.handle.net/10138/312929

https://doi.org/10.1111/joim.12903

acceptedVersion

Downloaded from Helda, University of Helsinki institutional repository.

This is an electronic reprint of the original article.

This reprint may differ from the original in pagination and typographic detail.

Please cite the original version. 
DR. CHARLOTTE BR ØNS (Orcid ID : 0000-0002-6653-9020)

DR. RASHMI PRASAD (Orcid ID : 0000-0002-4400-6741)

Article type : Original

\title{
Phenotypic and genotypic differences between Indian and Scandinavian women with gestational diabetes mellitus
}

\author{
Short running title: Diabetes during pregnancy: India and Scandinavia
}

Geeti P. Arora ${ }^{1,2}$, Mikael Åkerlund ${ }^{1}$, Charlotte Brøns ${ }^{3}$, Gunn-Helen Moen ${ }^{4,5}$ Niko S. Wasenius ${ }^{6,7}$, Christine Sommer ${ }^{4}$, Anne K. Jenum ${ }^{8}$, Peter Almgren ${ }^{1}$, Richa G. Thaman ${ }^{2}$, Marju Orho-Melander ${ }^{2}$, Johan Eriksson ${ }^{7}$, Elisabeth Qvigstad $^{4,9}$, Kåre Birkeland ${ }^{4,5}$, Kerstin Berntorp $^{1,10}$, Allan A. Vaag ${ }^{1,3,11}$, Leif Groop ${ }^{1,12}$, Rashmi B. Prasad ${ }^{1}$.

${ }^{1}$ Department of Clinical Sciences, Clinical Research Centre, Lund University, Malmö, Sweden

${ }^{2}$ Deep Hospital, Ludhiana, Punjab, India

${ }^{3}$ Department of Endocrinology (Diabetes and Metabolism), Rigshospitalet, Denmark

${ }^{4}$ Department of Endocrinology Morbid Obesity and Preventive Medicine, Oslo University Hospital, Oslo, Norway

${ }^{5}$ Institute of Clinical Medicine, Faculty of Medicine, University of Oslo, Oslo, Norway;

6. Folkhälsan Research Center, Biomedicum Helsinki, Haartmaninkatu 8, PO Box 63, 00014, Helsinki, Finland

${ }^{7}$ Department of General Practice and Primary Health Care, Diabetes and Obesity Research Program Research Programs Unit, University of Helsinki, Helsinki, Finland.

${ }^{8 .}$ Department of General Practice, Institute of Health and Society, University of Oslo,N-0318 Oslo, Norway.

9. Section of Specialized Endocrinology, Department of Endocrinology, Oslo University Hospital, Oslo, Norway

${ }^{10}$ Department of Endocrinology, Skåne University Hospital, Malmö, Sweden.

${ }^{11}$ Cardiovascular and Metabolic Disease (CVMD) Translational Medicine Unit, Early Clinical Development, IMED Biotech Unit, AstraZeneca, Gothenburg, Sweden.

${ }^{12}$ Finnish Institute of Molecular Medicine (FIMM), Helsinki University, Helsinki, Finland

This article has been accepted for publication and undergone full peer review but has not been through the copyediting, typesetting, pagination and proofreading process, which may lead to differences between this version and the Version of Record. Please cite this article as doi: 10.1111/joim.12903

This article is protected by copyright. All rights reserved. 
Corresponding author:

Rashmi B Prasad, Department of Clinical Sciences, Clinical Research Centre, Lund University, Malmö, Sweden.

Tel: +46 40391214 email: rashmi.prasad@med.lu.se

\section{Abstract}

Objective: Gestational diabetes mellitus (GDM) is a transient form of diabetes characterized by impaired insulin secretion and action during pregnancy. Population-based differences in prevalence exist which could be explained by phenotypic and genetic differences. The aim of this study was to examine these differences in pregnant women from Punjab, India and Scandinavia.

Methods: 85 GDM/T2D loci in European and/or Indian populations from previous studies were assessed for association with GDM based on Swedish GDM criteria in 4018 Punjabi Indian and 507 Swedish pregnant women. Selected loci were replicated in Scandinavian cohorts, Radiel (N=398, Finnish), STORK/STORK-G (N=780, Norwegian).

Results: Punjabi Indian women had higher GDM prevalence, lower insulin secretion and better insulin sensitivity than Swedish women. There were significant frequency differences of GDM/T2D risk alleles between both populations. rs7178572 at $H M G 20 A$, previously associated with GDM in South Indian and European women was replicated in North Indian women. The T2D risk SNP rs11605924 in the CRY2 gene was associated with increased GDM risk in Scandinavian but decreased risk in Punjabi Indian women. No other overlap was seen between GDM loci in both populations.

Conclusions: GDM is more common in Indian than Swedish women, which partially can be attributed to differences in insulin secretion and action. There was marked heterogeneity in the GDM phenotypes between the populations which could only partially be explained by genetic differences.

This article is protected by copyright. All rights reserved. 


\section{Introduction}

Gestational diabetes mellitus (GDM) is defined as "carbohydrate intolerance resulting in hyperglycemia of variable severity with onset or first recognition during pregnancy, excluding those with diabetes in pregnancy likely to represent overt diabetes mellitus" (http://www.who.int/). GDM develops when women no longer can increase their insulin secretion to meet the increased demands of insulin resistance during the second and third trimester of pregnancy ${ }^{1}$. The risk of GDM is exacerbated by age, obesity, and a family history of GDM and type 2 diabetes (T2D) ${ }^{2}$; however, the exact etiology is unknown. Women with GDM are at increased risk of gestational hypertension, pre-eclampsia, and T2D, as well as metabolic syndrome later in life ${ }^{3}$. Untreated GDM predisposes to adverse neonatal outcome and predicts future development of T2D in both the mothers and offspring 4 .

Ethnicity has a great impact on the prevalence of GDM which of GDM differs between $1 \%$ and $10-35 \%$ in different populations and applying different criteria ${ }^{5,6}$. Individuals of Asian descents have 2-7 -fold greater risk of developing GDM than their Caucasian counterparts ${ }^{7}$. These differences can have several explanations including differences in predisposing risk factors including diet and lifestyle ${ }^{8}$, but also genetics and diagnostic criteria applied ${ }^{9}$.

Family history of T2D or previous history of GDM increases risk for developing GDM during pregnancy. Several candidate gene studies have confirmed a role for T2D risk loci in GDM. To our knowledge, only one Asian GWAS study on GDM in Korean women has been published ${ }^{10}$. Few studies have examined the genetic susceptibility to GDM in the Indian population; these included two studies in South Indian women and reported association of variants in the CDKAL1, HMG2OA and HNF4A genes with GDM ${ }^{11,12}$. It is quite possible that the genetic background contributing to GDM differs between women of North Indian and of 
Scandinavian origin and could explain some disparities in the prevalence of GDM. To address these questions, we examined phenotypic and genetic differences in pregnant women with GDM from India and Sweden.

\section{Methods}

\section{Study population and GDM diagnosis}

PunjabiGDM study: A multistage protocol was applied for recruiting study participants between 2009 and 2012 in a representative group of 5100 pregnant women from Punjab. All women between gestational weeks $24-28$ weeks visiting selected study sites, both urban and rural for antenatal checkup were screened. Information of demographic factors including diet, age, family history of diabetes, BMI, location (urban / rural), education status and religion was obtained in a standard questionnaire by trained health-care professionals. Written material was provided in three languages (Hindi, English and Punjabi). Consent was obtained from each study participant after full explanation of the purpose and nature of all procedures used.

The project was approved by Independent ethics committee, Ludhiana in 2009 (registered with Office of Drugs Controller General (India) Directorate General of Health Service). All participants underwent a 75-g OGTT as previously described ${ }^{5,13}$. Based on availability of DNA and clinical data a total of 4018 women were included in the study.

\section{Scandinavian Cohorts}

Malmö Study: From a total of 188 women with GDM referred to the Department of Endocrinology in Malmö, Sweden, between 1995 and 1999, 83 women of Swedish ethnicity were included in the present study. A 75-g OGTT was performed at the 28th week of 
gestation. The OGTT was then repeated with venous measurements of blood glucose concentrations at $0,30,60$ and $120 \mathrm{~min}$ with simultaneous measurements of insulin concentrations. Blood glucose values were converted to plasma glucose by multiplying by a factor of 1.11 according to the IFCC recommendation ${ }^{14}$.

Mamma study: Pregnant women giving birth in the County of Skåne in southern Sweden between 2003 and 2005 were recruited to the Mamma study. A 75-g OGTT was offered to all the women at 27-28 week of gestation as part of routine antenatal care. From a total of 424 women of Swedish ancestry, 89 women with GDM (2-h capillary plasma glucose concentration $\geq 10.0 \mathrm{mmol} / \mathrm{l})$, and 335 women without GDM (2-h capillary plasma glucose concentration $<9.9 \mathrm{mmol} / \mathrm{l}$ ) with DNA available were included in the study.

Informed consent was obtained from each study participant after full explanation of the purpose and nature of all procedures used and the studies were approved by the Ethics Committee of Lund University. Glucose concentrations were measured using HemoCue devices (HemoCue, Ängelholm, Sweden).

\section{Diagnosis of GDM}

In order to maintain consistency between studies, GDM in the present study was defined as 2 -h plasma blood glucose concentration $\geq \mathbf{1 0}$ mmol / (2-h capillary blood glucose concentration of $\geq 9.0 \mathrm{mmol} / \mathrm{l}$ ) in accordance with the definition in the Malmö study, where only 2 -h glucose values were available.

\section{Biochemical measurements}

Serum insulin concentrations were measured with an enzyme-linked immunosorbent assay (ELISA, Dako, Glostrup, Denmark), and homeostasis model assessment (HOMA2-B and 
HOMA2-IR) was used for estimation of insulin secretion and action, using the HOMA2 calculator v2.2.3 (http://www.dtu.ox.ac.uk/homacalculator/) ${ }^{15}$.

\section{Genotyping}

DNA was extracted from buffy coats using the QIAGEN Autopure W kit. Six SNPs previously associated with GDM and /or T2D in Indian people in either GWAS or candidate studies ${ }^{11,16-18}$ and 79 SNPs associated with T2D/GDM from previous GWAS studies with replication, with overall p-values $<5 \times 10^{-8}{ }^{19}$ (supplementary table 1 ) were genotyped in the current study using a Sequenom mass ARRAY platform or Taqman. All SNPs passed the Bonferroni threshold of $<0.0006$ for Hardy-Weinberg equilibrium test.

\section{Statistical analyses}

Anthropomorphic and glycemic measures are presented as means \pm SEM. Significance of differences between group means was tested by the Mann-Whitney $U$ test or analysis of variance or covariance (ANCOVA) with BMI and age as covariates. Inverse normal transformation was used to normalize data with skewed distributions.

Allele and genotype frequencies were compared between groups by chi-square or Fisher's exact test. Association of selected SNPs with GDM was assessed by logistic regression analysis adjusted for maternal age and results presented as ORs with their 95\% confidence intervals (CI) in plink (plink v1.09). Alleles were also analyzed for association with glucose, insulin and HOMA2-B and HOMA2-IR) using linear regression model adjusted for age.

Two-sided p values of less than 0.05 were considered statistically significant. For the Indian study population, power to detect association with GDM (125 cases and 3893 controls) for 79 markers at a significance level of 0.05, was 0.04 under an additive model and 0.12 under a 
multiplicative model at $0.50 \mathrm{MAF}$ and OR of 1.5. For the Swedish cohort with 245 cases and 335 controls, the corresponding figures were 0.06 and 0.17 respectively. For association with quantitative traits, power to detect an association was 1 at alpha 0.05 for an allele frequency of $0.3^{20}$. Polygenic risk scores which is the sum of trait-associated alleles across many genetic loci, typically equally weighted for effect sizes, were calculated using PLINK and regressed against the phenotype. In order to construct genetic risk scores (GRS), we used SNPs from previous GWAS studies on T2D risk and previously published candidate studies for GDM. We constructed unweighted polygenetic genetic risk scores using the Plink 1.9 software package. We constructed scores using (1) known GDM variants only (2) GDM variants reported in India, (3) T2D loci from previous GWAS study (i.e. genome-wide significant SNPs), (4) T2D loci showing genome wide significance in Indian populations alone, (5) All reported T2D and GDM loci and (6) T2D and GDM loci from Indian populations studies alone (supplementary table 1). Twelve SNPs previously associated with insulin secretion indices and 5 SNPs with insulin resistance were here used to construct genetic risk scores (GRS) for insulin secretion and action respectively using PLINK in women with GDM ${ }^{21}$ (supplementary table 1).

To compare the relationship between (i) HOMA2-B and BMI, (ii) HOMA2-B and HOMA2IR and (iii) HOMA2-IR and BMI in non-diabetic women from Indian and European studies, we selected non-diabetic women from the Prevalence, Prediction and Prevention of diabetes (PPP)-Botnia Study, a population-based study in Western Finland started in $2004^{22}$, due to lack of data on normal glucose tolerance (NGT) women from the Malmö and Mamma studies. For the present analyses, non-diabetic women (age : mean $\pm \mathrm{SD}=49.59 \pm 15.75$ ) were selected and age adjusted residuals of HOMA2-B, HOMA2-IR and BMI were calculated and compared for (i) and (iii) and age and BMI adjusted residuals were calculated for (ii) .

This article is protected by copyright. All rights reserved. 
$\mathrm{F}_{\mathrm{ST}}$ analysis for estimating genetic differentiation between Indian and Scandinavian study populations overall as well as for affected women only was computed using the Weir and Cockerham method ${ }^{23}$ implemented in vcftools ${ }^{24}$.

\section{Replication in European study populations}

The Radiel study comprising 398 women (age $=32.7 \pm 4.4$ years, mean BMI $=32.8 \mathrm{~kg} / \mathrm{m} 2$ SD, 8 with GDM) were included for replication of 18 selected loci showing nominal significance in either Indian or Swedish studies or both. Two SNPs including rs4402960 and rs 10010131 had HWE $<0.05$ in controls and were excluded.

The STORK study is a prospective cohort of 1031 healthy pregnant women of Scandinavian heritage who registered for obstetric care at the Oslo University Hospital Rikshospitalet from 2001 to $2008^{25}$. Exclusion criteria were multiple pregnancies, known history of type 1 or type 2 diabetes mellitus, and severe chronic diseases (pulmonary, cardiac, gastrointestinal, or renal). Results of a $75 \mathrm{~g}$ OGTT, age, height and weight were recorded at inclusion at gestational weeks 14-16. The OGTT test was repeated at the third visit in gestational week 30-32. The study was approved by the Norwegian "Regional Committee for Medical Health Research Ethics South East”. Written consents were obtained for all participants. In STORK 512 women with European ancestry were selected for the present study (8 cases and 504 controls, age: $31.6 \pm 3.78$ years).

The STORK Groruddalen study (STORK-G) is a population-based cohort which included 823 healthy women attending three public mother child health clinics for antenatal care in the multi-ethnic area of Groruddalen, Oslo, Norway ${ }^{26}$. Women were eligible if they: 1) lived in the study districts; 2) planned to give birth at one of two study hospitals; 3) were $<20$ weeks 
pregnant; 4) could communicate in Norwegian or any of the eight translated languages; 5) were able to give an informed consent. Women with pre-gestational diabetes or in need of intensive hospital follow-up during pregnancy were excluded. The participation rate was 74 $\%$, varying from $63.9 \%$ to $82.6 \%$ across ethnic groups. The study was approved by the Norwegian "Regional Committee for Medical Health Research Ethics South East". Written consents were obtained for all participants. In STORK-G, 268 women with European ancestry were included (4 cases and 264 controls, age: $30.7 \pm 4.51$ years).

Meta-analysis: of the selected SNPs in the European studies was performed using METAL (http://csg.sph.umich.edu/abecasis/metal/) with beta coefficients for directionality and weighted on the study population.

eQTL lookups: The association of SNPs with gene expression in human pancreatic islets was looked up in data from RNAseq data from 191 donors from a previously published study 27.

\section{Results}

\section{Clinical characteristics}

Applying Swedish GDM criteria cut-offs, the prevalence of GDM in the PunjabiGDM study was $3.11 \%$ (125 out of 4018 women). Swedish women with GDM were $>10$ years older $(\mathrm{p}=$ $\left.1.21 \times 10^{-40}\right)$ and had higher BMI $\left(28.09 \pm 0.64\right.$ vs $\left.24.08 \pm 0.42, \mathrm{p}=3.76 \times 10^{-07}\right)$ than the Punjabi women (table 1).

This article is protected by copyright. All rights reserved. 
The Indian GDM women had higher fasting glucose $\left(5.72 \pm 0.15\right.$ vs $\left.4.79 \pm 0.10,1.60 \times 10^{-5}\right)$ and 2 -h glucose $\left(12.07 \pm 0.20\right.$ vs $\left.10.99 \pm 0.08, \mathrm{p}=3.13 \times 10^{-02}\right)$ which associated with lower fasting insulin $\left(51.8 \pm 5.35\right.$ vs $\left.78.17 \pm 12.67, \mathrm{p}=3.74 \times 10^{-06}\right)$ and HOMA2-B $(76.6 \pm 3.83$ vs 123.98 $\pm 7.54, \mathrm{p}=2.99 \times 10-9)$ as well as better insulin sensitivity estimated by HOMA2-IR $(1.036 \pm 0.97$ vs $1.26 \pm 0.097, \mathrm{p}=0.001)$ compared with Swedish GDM women adjusted for BMI and age (table 1).

\section{Insulin secretion, resistance and BMI in Indian and Scandinavian women}

We examined the relationship of HOMA2-B, HOMA2-IR and BMI in women with NGT in Indian and Swedish women. Since we lacked OGTT data from Swedish pregnant nondiabetic women, we here used OGTT from women with NGT from the Botnia-PPP cohort. There was a stronger relationship between BMI and insulin secretion as well as insulin resistance in Scandinavian women compared to Indian. Here we found significant differences in the relationship between HOMA2-B - HOMA2-IR ( $\mathrm{p}=0.0028$, figure 1a), HOMA2-B BMI $\left(\mathrm{p}=8.48 \times 10^{-17}\right.$, figure $\left.1 \mathrm{~b}\right)$ and HOMA2-IR - BMI $\left(\mathrm{p}=8.11 \times 10^{-25}\right.$, figure $\left.1 \mathrm{c}\right)$ between Indian and Scandinavian women with NGT.

\section{Frequency differences and population differentiation for GDM and T2D associated SNPs between populations}

Significant differences were observed for minor allele frequencies of SNPs at the CDKAL1, SLC30A8, IGF2BP2, ADCY5, G6PC2, WFS1, HHEX/IDE and MTNR1B loci between all pregnant women from the Indian and Swedish studies (supplementary figure 1). $\mathrm{F}_{\mathrm{ST}}$ analysis 
showed clear genetic differentiation at the rs998451 (TMEM163), rs8042680 (PRC1), and rs1799999 (PPP1R3A) loci whereas differences at 14 loci including rs560887 (G6PC2) and rs9552911 (SGCG) loci were less pronounced (figure 2).

When only focusing on women with GDM, we observed significant differences in frequency of GDM risk alleles rs560887 in G6PC2 ( $\mathrm{p}=0.0008)$, rs11708067 in ADCY5 ( $\mathrm{p}=0.005)$, rs10010131 in WFS1 $(\mathrm{p}=<0.0001)$ and $\mathrm{rs} 10811661(\mathrm{p}=0.0073)$ in $C D K N 2 B$ genes between Indian and Swedish women with GDM were seen (supplementary table 2). F $_{\text {ST }}$ values here was identical to that seen when the entire study population was considered with the exception of DUSP9, HHEX, and WFS1 which showed moderate differentiation in GDM women whereas very little when all women were considered (figure 2).

\section{Association of genetic loci with GDM in Indian and Swedish women}

SNPs previously associated with GDM/T2D in India. The risk allele C of rs7178572 SNP near HMG20A was nominally associated with risk of GDM in Indian but not in Swedish women $(\mathrm{p}=0.03$, table 2$)$, thereby replicating previous findings in Indian populations. This SNP also showed nominally significant association with GDM in the STORK-G study, which predominantly comprised multi-ethnic women. rs7178572 is an eQTL for the PSTPIP1 ( $\mathrm{p}=$ 0.003 ) and HMG20A ( $\mathrm{p}=0.007)$ genes in human pancreatic islets (Supplementary table 4).

The Asp/Tyr missense variant of SNP rs1799999 in the PP1RR3A gene, which previously has been shown to associate with T2D risk in Jat Sikhs ${ }^{18}$, showed a trend towards association in Indian women $(\mathrm{p}=0.06)$ (table 2$)$. The variant was also nominally associated with decreased 2-hour (2-h) insulin in Swedish women ( $\mathrm{p}=0.02$, supplementary table 3).

This article is protected by copyright. All rights reserved. 
SNPs previously associated with GDM or T2D in Europeans: Of 12 SNPs previously associated with Scandinavian GDM ${ }^{28,29}$ (Supplementary table 1), the rs1111875 SNP near the HHEX/IDE genes was nominally associated with GDM in Swedish women $(\mathrm{p}=0.031$, table 3). While the association of the SNP with GDM in the other European cohorts was not significant, the direction of effect was consistent with that in the Swedish study in two out of three studies (table 3). The rs1111875 variant influences expression of NHP2P1 and BTAF1 genes in human pancreatic islets (supplementary table 4). The frequency of rs1111875 differed between Indian and Swedish women $(\mathrm{p}=<0.0001$, supplementary table 2, supplementary figure 1).

The risk allele rs11708067 in the ADCY5 gene was associated with increased 2-h glucose ( $\mathrm{p}=$ 0.037), and decreased HOMA2-B $(\mathrm{p}=0.010)$ in Swedish GDM women (supplementary table 3). The same SNP was associated with 2-h glucose in all Swedish women (GDM and non$\operatorname{GDM})(\beta=0.12 \pm 0.04, \mathrm{p}=0.004)$.

The rs11605924 SNP in the intron of the $C R Y 2$ gene was nominally associated with GDM in both study populations (table 4). Interestingly, the T2D risk allele A was protective in the Indian population $(\mathrm{OR}=0.67, \mathrm{p}=0.0026$, table 4$)$ whereas it was associated with risk in the Swedish women $(\mathrm{OR}=1.44, \mathrm{p}=0.012$, table 4$)$. A similar direction of effect was observed in the Radiel, STORK and STORK-G studies and the meta-analysis of European studies showed a significant association with GDM $(\mathrm{p}=0.014$, table 4$)$. The same SNP showed differences in frequencies between Indian and Swedish women $(p=0.0004$, supplementary table 2, supplementary fig 1). The rs11605924 nominally influenced expression of CRY2 in human pancreatic islets (supplementary table 4).

This article is protected by copyright. All rights reserved. 
The rs8090011 SNP in an intron of the LAMA1 gene was nominally associated with GDM risk in Swedish women (table 4). The same SNP also associated with decreased 2-h insulin concentration (supplementary table 4).

SNPs rs12571751 in the intron of ZMIZ1, rs5945326 near DUSP9, and rs2237895 in the intron of $K C N Q 1$ were nominally associated with GDM in Swedish women whereas only the rs7593730 SNP near RBMS1 was associated with GDM risk in Indian women (table 4).

Genetic risk scores (GRS) based on all T2D / GDM loci predicted GDM risk in Swedish but not in Indian women ( $p=0.036$, table 5$)$ whereas GRS based on previous GDM associations in Indian populations predicted GDM risk in India $(\mathrm{p}=0.042$, table 5). GRS for insulin resistance was $0.11( \pm 0.1, \mathrm{p}=0.49)$ for Swedish whereas $0.13( \pm 0.07, \mathrm{p}=0.059)$ for Indian women. GRS for insulin secretion was $-0.034( \pm 0.06, \mathrm{p}=0.53)$ for Swedish and -0.078 $( \pm 0.039, \mathrm{p}=0.42)$ for Indian women.

\section{Discussion}

The key findings in the current study were that Indian and Swedish women with GDM showed clear differences in measures of insulin secretion and action (i.e. HOMA2-B and HOMA2-IR), which cannot fully could be accounted for by genetic effects alone. Despite being on average 10 years younger, North Indian women had a higher prevalence $(3.11 \%)$ of GDM than previously reported in Swedish women (2.6\%) from comparable time periods ${ }^{6}$. Of note, the prevalence figure of 2.6\% during 2009-2012 was based on a study population of mixed ethnicity residing in Sweden, and a lower prevalence could be expected if only

Swedish women were included (estimated 1.2-1.5\%) ${ }^{30}$. This is consistent with previous 
reports showing higher GDM frequency in populations with a high frequency of T2D ${ }^{31}$. The prevalence of T2D from previous studies was higher in India than in Sweden $(8.3-9.4 \%$ vs $6.8 \%)^{32,33}$.

Indian women had lower HOMA2-B, which was associated with lower BMI and better insulin sensitivity than Swedish GDM women. The better insulin sensitivity could at least partially be a corollary of the lower BMI (supplementary figure 2). As Indian women seem to develop GDM at lower BMI and with better insulin sensitivity, this could point at a more severe defect in insulin secretion, which was also supported by lower HOMA2-B. However, we need to acknowledge that HOMAs are only surrogate markers for insulin secretion and action.

Previously, 6 loci have been associated with T2D or GDM in India ${ }^{11,16-18}$. Of them, the rs7178572 SNP near the HMG20A gene was associated with GDM in Indian but not in Swedish women. Considering the effect sizes observed in both populations, this is likely an effect of low power in the Swedish studies and to a lesser extent heterogeneity, given that this SNP has also been associated with T2D in other European populations ${ }^{34}$. The power to detect association of rs7178572 (HMG20A) with GDM at a significance level of 0.05 was 0.76 . Notably, only when we used the older WHO1999 criteria with higher cut-off values for glucose, we could observe this association. This is consistent with our previous reports based on the same study population (PunjabiGDM), rs7178572 did not associate with GDM diagnosed either using WHO1999 or WHO2013 criteria ${ }^{35}$. Interestingly, a GRS constructed of previous GDM associations in Indian populations including this SNP significantly predicted GDM in the Indian but not Swedish women. Also of interest is that moderate genetic differentiation observed at this locus $\left(\mathrm{F}_{\mathrm{ST}}=0.07\right)$. It should be also noted that the Indian population has complex genetic origins, with high genetic diversity between the North

This article is protected by copyright. All rights reserved. 
and South. The Punjabi-Indian population belongs to the "Ancestral North Indians" group and shares genetic similarities with those from Middle East, Central Asia and to some extent, Europe whereas the South Indian population belongs to the genetically distinct "Ancestral South Indian" group ${ }^{36}$. Due to differences in haplotype structures, variants associated with GDM in the South Indian population might not necessarily associate with GDM in the North India. Earlier studies have shown a weak association of rs7178572 with PSTPIP1 gene expression in lymphoblastoid cell lines ${ }^{34}$. Here we showed that this SNP also was an eQTL in human pancreatic islets influencing expression of both PSTPIP1 and HMG20A. The Proline-Serine-Threonine Phosphatase Interacting Protein 1 (PSTPIP1) gene is a tyrosine phosphatase that inhibits T-cell activation upon T-cell receptor (TCR) and CD28 engagement, regardless of CD2 co-stimulation ${ }^{37}$. The HMG20A gene had higher expression in islets than in muscle and adipose tissue ${ }^{38}$ and a transient increase in expression levels were observed upon glucose stimulation ${ }^{38}$. HMG20A has been reported to be down-regulated in T2D and T1D islets, and knockdown of HMG2OA decreased expression of NEUROD, INS and $G K$ with an accompanying impairment in GSIS ${ }^{38}$. Therefore, this SNP could through its eQTL effect on $H M G 20 A$ expression in islets be a plausible candidate gene for GDM.

The early GWAS SNP rs1111875 near the HHEX/IDE genes was associated with GDM risk in Swedish women but not Indian. Notably, the T2D risk SNP rs11605924 in CRY2 showed a protective effect against GDM in Indian but conferred risk in Swedish women. The power to detect association of rs11605924 (CRY2) with GDM at a significance level of 0.05 was 0.85 . This protective effect was consistent even when WHO1999 criteria was applied in our previous study on the same population ${ }^{35}$. CRY2 encodes the circadian rhythm gene cryptochrome 2 , and is a target for the CLOCK-BMAL1, which are core components of the endogenous clock. The $C R Y 2$ variant is also associated with fasting glucose and reduced liver fat content in human liver ${ }^{39}$. CRY2 mRNA expression has been associated with hepatic 
triglyceride content ${ }^{39}$ suggesting that $C R Y 2$ could serve as a switch between fat and glucose metabolism in the liver ${ }^{39}$. Interestingly, as the same allele had effects in opposite directions in Indian and Swedish populations, the question rises whether risk seen in the Swedish population could be related to marked differences in circadian rhythm during seasons in Sweden, which is lacking in India. However, this finding needs to be replicated in other Indian studies.

In our previous study, we observed that the T2D risk SNP in the TCF7L2 gene did not associate with GDM either using WHO1999 or WHO2013 criteria $^{35}$. However, using the Swedish GDM diagnostic criteria (2-h capillary blood glucose concentration $\geq 10 \mathrm{mmol} / \mathrm{l}$ ), we see a trend towards an association Increasing fasting glucose cut-offs could further capture the extreme GDM cases and a stronger signal could be obtained. Alternately, this could also be due to population-based differences ${ }^{35}$.

Interestingly, significant frequency differences were observed for 6 out of 12 GDM risk alleles, two of which showed a reversal of major and minor alleles. High to moderate genetic differentiation was observed at 17 loci. Of particular interest was the highest differentiation observed at the TMEM163 locus, which had previously only shown an association with T2D in Indian but not European studies. A previous study of $12 \mathrm{~T} 2 \mathrm{D}$ risk alleles showed decreasing frequencies going from Africa to Europe to East Asia. These decreasing frequencies were associated with different risk of T2D, with the highest in Africa and lowest in Asia. The authors hypothesized that these differences might be caused by optimizing energy storage and usage in environments with inconsistent energy intake ${ }^{40}$. CRY2 could also potentially represent such an example.

This article is protected by copyright. All rights reserved. 
There were significant differences in the relationship between insulin secretion and insulin resistance or between insulin resistance and BMI between glucose-tolerant Indian and Swedish women, which could not be explained by differences in age. A GRS comprised of all previously reported GDM and T2D loci from European studies predicted GDM in the Swedish but not Indian women. These data support the view that differences between these ethnic groups could be partially explained by genetic differences. Since most T2D loci were identified in European ancestry cohorts, this could reflect differences in tagging SNPs due to differences haplotypes between populations. This could also be partly attributed to the differences in anthropometry between Indian and Scandinavian populations, with the former manifesting the distinct "thin-fat" phenotype from birth ${ }^{34,35}$.

The criteria applied to diagnose GDM markedly influence risks. WHO1999 clearly identifies a more severe dysregulation of glucose metabolism than the other criteria. On the other hand, WHO 2013 is designed to identify risk of adverse pregnancy outcomes in the offspring. The PRS derived from T2D loci identified a shared genetic background between GDM and T2D in India, but not in Sweden probably due to too low power. This does not exclude the possibility that a GWAS could identify shared genetic background also for the other criteria and thereby risk for offspring.

A limitation of the study was the low power in some of the studies to allow multiple testing; we hope that the meta-analysis of Scandinavian studies including Radiel, STORK and STORK-G compensated for this to some extent. Additionally, a proportion of women diagnosed with GDM based on WHO1999 or WHO2013 criteria were excluded due to application of Swedish GDM criteria. Despite differences in study settings, the stringent 
GDM diagnostic criteria applied (based on Sweden criteria) should identify the most extreme cases. Nevertheless this is largest comparative study comparing GDM between European and non-European populations and further, the first study comparing GDM in India with that of Europe.

Hypertension during pregnancy is an important aspect, however this was unfortunately not measured for all participants due to limitations in the screening process in many rural areas of screening and is one of the limitations of the study.

Taken together Indian women develop GDM at lower BMI and better insulin sensitivity than Scandinavian women. This points at problems to increase insulin secretion to meet the increased demands imposed by even small increases in insulin resistance during the third trimester. The genetic contribution to GDM seems to be shared with T2D.

\section{Author Contributions}

GPA, MA, CB, NW and RPB researched data and reviewed/edited the manuscript. RPB, MA, NW, GHM, and PA analyzed the data. RPB, GPA, AAV, KB, LG contributed to study design and reviewed/edited the manuscript. RT, MOM, NW, GHM, CS, EQ, AKJ, JE, KB, $\mathrm{KIB}$, AV reviewed/edited the manuscript. $\mathrm{KB}$ and $\mathrm{LG}$ contributed to the discussion and extensively reviewed/edited the manuscript. RPB wrote the manuscript.

\section{Acknowledgements}

We wish to thank the World Diabetes Foundation for providing a database in Punjab, India and Mr Raman Gautam for coordinating screening and sampling, Dr Baldeep and his team 
from Deep Hospital, Ludhiana, India for providing the infrastructure for the study and the government health authorities of Punjab for supporting the study. We gratefully acknowledge Gabriella Gremsperger, Maria Sterner, Malin Neptin and Jasmina Kravic for their technical assistance, sampling and organization of data. Finally, we thank all the participating pregnant women in the study.

Funding was received from the World Diabetes Foundation, Denmark, the Danish Strategic Research Council, Novo Nordisk Foundation, the Augustinus Foundation, Center for Physical Activity Research to AV, by Deep Hospital and Ved Nursing Home and Eye Hospital, Ludhiana, India to GPA, Sydvästra Skånes Diabetesförening, the Swedish Research Council, Hospital Region of Region Skåne, the Swedish Research Council Networking Grant, the European Research Council, and Norwegian South- Eastern Health Authority.

\section{Conflict of interest statement}

Dr. Prasad reports other from Novo Nordisk, other from AstraZeneca, outside the submitted work:

$\mathrm{CB}$ is a stockholder in Novo Nordisk A/S and AV is employed by AstraZeneca. On behalf of all the other authors, Dr. Prasad B has nothing to disclose. RPB and LG take responsibility for the contents of the article.

\section{Data availability statement}

The datasets generated during and/or analysed during the current study are available from the corresponding author on reasonable request.

This article is protected by copyright. All rights reserved. 
1. Ryan EA, O'Sullivan MJ, Skyler JS. Insulin action during pregnancy. Studies with the euglycemic clamp technique. Diabetes. 1985;34(4):380-389.

2. Bloomgarden ZT. Gestational diabetes mellitus and obesity. Diabetes care. 2010;33(5):e60-65.

3. Carr DB, Utzschneider KM, Hull RL, et al. Gestational diabetes mellitus increases the risk of cardiovascular disease in women with a family history of type 2 diabetes. Diabetes care. 2006;29(9):2078-2083.

4. Kaaja R, Ronnemaa T. Gestational diabetes: pathogenesis and consequences to mother and offspring. Rev Diabet Stud. 2008;5(4):194-202.

5. Arora GP, Thaman RG, Prasad RB, et al. Prevalence and risk factors of gestational diabetes in Punjab, North India: results from a population screening program. European journal of endocrinology / European Federation of Endocrine Societies. 2015;173(2):257-267.

6. Ignell C, Claesson R, Anderberg E, Berntorp K. Trends in the prevalence of gestational diabetes mellitus in southern Sweden, 2003-2012. Acta Obstet Gynecol Scand. 2014;93(4):420-424.

7. Silva JK, Kaholokula JK, Ratner R, Mau M. Ethnic differences in perinatal outcome of gestational diabetes mellitus. Diabetes care. 2006;29(9):2058-2063.

8. Galtier F. Definition, epidemiology, risk factors. Diabetes Metab. 2010;36(6 Pt 2):628-651.

9. Buckley BS, Harreiter J, Damm P, et al. Gestational diabetes mellitus in Europe: prevalence, current screening practice and barriers to screening. A review. Diabetic medicine : a journal of the British Diabetic Association. 2012;29(7):844-854.

10. Kwak SH, Kim SH, Cho YM, et al. A genome-wide association study of gestational diabetes mellitus in Korean women. Diabetes. 2012;61(2):531-541.

11. Kanthimathi $S$, Chidambaram M, Bodhini $D$, et al. Association of recently identified type 2 diabetes gene variants with Gestational Diabetes in Asian Indian population. Mol Genet Genomics. 2017;292(3):585-591.

12. Kanthimathi S, Chidambaram M, Liju S, et al. Identification of Genetic Variants of Gestational Diabetes in South Indians. Diabetes Technol Ther. 2015;17(7):462-467.

13. Arora GP, Almgren P, Thaman RG, et al. Insulin secretion and action in North Indian women during pregnancy. Diabet Med. 2017.

14. Burnett RW, D'Orazio P, Fogh-Andersen N, et al. IFCC recommendation on reporting results for blood glucose. Clin Chim Acta. 2001;307(1-2):205-209.

15. Levy JC, Matthews DR, Hermans MP. Correct homeostasis model assessment (HOMA) evaluation uses the computer program. Diabetes Care. 1998;21(12):21912192.

16. Saxena R, Saleheen D, Been LF, et al. Genome-wide association study identifies a novel locus contributing to type 2 diabetes susceptibility in Sikhs of Punjabi origin from India. Diabetes. 2013;62(5):1746-1755.

17. Tabassum R, Chauhan G, Dwivedi OP, et al. Genome-wide association study for type 2 diabetes in Indians identifies a new susceptibility locus at 2q21. Diabetes. 2013;62(3):977-986.

18. Sokhi J, Sikka R, Raina P, et al. Association of genetic variants in INS (rs689), INSR

This article is protected by copyright. All rights reserved. 
(rs1799816) and PP1G.G (rs1799999) with type 2 diabetes (T2D): a case-control study in three ethnic groups from North-West India. Mol Genet Genomics. 2016;291(1):205-216.

19. Prasad RB, Groop L. Genetics of type 2 diabetes-pitfalls and possibilities. Genes (Basel). 2015;6(1):87-123.

20. Purcell S, Cherny SS, Sham PC. Genetic Power Calculator: design of linkage and association genetic mapping studies of complex traits. Bioinformatics. 2003;19(1):149-150.

21. Purcell S, Neale B, Todd-Brown K, et al. PLINK: a tool set for whole-genome association and population-based linkage analyses. Am J Hum Genet. 2007;81(3):559-575.

22. Isomaa B, Forsen B, Lahti $\mathrm{K}$, et al. A family history of diabetes is associated with reduced physical fitness in the Prevalence, Prediction and Prevention of Diabetes (PPP)-Botnia study. Diabetologia. 2010;53(8):1709-1713.

23. Weir BS, Cockerham CC. Estimating F-Statistics for the Analysis of Population Structure. Evolution. 1984;38(6):1358-1370.

24. Danecek P, Auton A, Abecasis G, et al. The variant call format and VCFtools. Bioinformatics. 2011;27(15):2156-2158.

25. N. V. Modifiable determinants of newborn macrosomia and birth complications. PhD thesis [PhD ]: University of Oslo, Faculty of Medicine2010.

26. Jenum AK, Sletner L, Voldner N, et al. The STORK Groruddalen research programme: A population-based cohort study of gestational diabetes, physical activity, and obesity in pregnancy in a multiethnic population. Rationale, methods, study population, and participation rates. Scandinavian journal of public health. 2010;38(5 Suppl):60-70.

27. Ottosson-Laakso E, Krus U, Storm P, et al. Glucose-Induced Changes in Gene Expression in Human Pancreatic Islets: Causes or Consequences of Chronic Hyperglycemia. Diabetes. 2017;66(12):3013-3028.

28. Lauenborg J, Grarup N, Damm P, et al. Common type 2 diabetes risk gene variants associate with gestational diabetes. The Journal of clinical endocrinology and metabolism. 2009;94(1):145-150.

29. Huopio H, Cederberg H, Vangipurapu J, et al. Association of risk variants for type 2 diabetes and hyperglycemia with gestational diabetes. European journal of endocrinology / European Federation of Endocrine Societies. 2013;169(3):291-297.

30. Eades CE, Cameron DM, Evans JMM. Prevalence of gestational diabetes mellitus in Europe: A meta-analysis. Diabetes research and clinical practice. 2017;129:173-181.

31. Diabetes and impaired glucose tolerance in women aged 20-39 years. World Health Organization Ad Hoc Diabetes Reporting Group. World Health Stat Q. 1992;45(4):321-327.

32. Andersson T, Ahlbom A, Carlsson S. Diabetes Prevalence in Sweden at Present and Projections for Year 2050. PloS one. 2015;10(11):e0143084.

33. Anjana RM, Pradeepa R, Deepa M, et al. Prevalence of diabetes and prediabetes (impaired fasting glucose and/or impaired glucose tolerance) in urban and rural India: phase I results of the Indian Council of Medical Research-INdia DIABetes (ICMR-INDIAB) study. Diabetologia. 2011;54(12):3022-3027.

34. Kooner JS, Saleheen D, Sim X, et al. Genome-wide association study in individuals of South Asian ancestry identifies six new type 2 diabetes susceptibility loci. Nat Genet.

This article is protected by copyright. All rights reserved. 
2011;43(10):984-989.

35. Arora GP, Almgren $P$, Brons $C$, et al. Association between genetic risk variants and glucose intolerance during pregnancy in north Indian women. BMC Med Genomics. 2018;11(1):64.

36. Bamshad M, Kivisild T, Watkins WS, et al. Genetic evidence on the origins of Indian caste populations. Genome Res. 2001;11(6):994-1004.

37. Marcos T, Ruiz-Martin V, de la Puerta ML, et al. Proline-serine-threonine phosphatase interacting protein 1 inhibition of T-cell receptor signaling depends on its SH3 domain. FEBS J. 2014;281(17):3844-3854.

38. J.M. Mellado-Gil EF-M, P.I. Lorenzo, J.C. Reyes, F.J. Bermúdez-Silva, M. AguilarDiosdado and B. Gauthier. THE DIABETES-LINKED FACTOR HMG20A TARGETS ISLET GENES INVOLVED IN INSULIN SECRETION. COMUNICACIONES ORALES. 22-26 April, 2016.

39. Machicao F, Peter A, Machann J, et al. Glucose-Raising Polymorphisms in the Human Clock Gene Cryptochrome 2 (CRY2) Affect Hepatic Lipid Content. PloS one. 2016;11(1):e0145563.

40. Chen $\mathrm{R}$, Corona $\mathrm{E}$, Sikora $\mathrm{M}$, et al. Type 2 diabetes risk alleles demonstrate extreme directional differentiation among human populations, compared to other diseases. PLoS Genet. 2012;8(4):e1002621.

Table 1. Clinical characteristics of Indian and Swedish women with GDM (diagnosed based on 2 -h glucose cut-offs $>=10 \mathrm{mmol} / \mathrm{l})$. Mean \pm SEM are represented. P-values are calculated based on inverse normal transformed data.

\begin{tabular}{|c|c|c|c|c|c|}
\hline Variable & Swedish & N (Swedish) & Indian & $\mathbf{N}$ (Indian) & P value \\
\hline Age (years) & $31.78 \pm 0.36$ & 149 & $20.97 \pm 0.33$ & 125 & $1.21 \times 10^{-40}$ \\
\hline BMI $\left(\mathrm{kg} / \mathrm{m}^{2}\right)$ & $28.09 \pm 0.64$ & 56 & $24.08 \pm 0.42$ & 125 & $3.76 \times 10^{-07}$ \\
\hline Fasting glucose $^{\mathrm{a}}(\mathrm{mmol} / \mathrm{l})$ & $4.79 \pm 0.10$ & 49 & $5.72 \pm 0.15$ & 125 & $1.60 \times 10^{-05}$ \\
\hline 2-h glucose ${ }^{\mathrm{a}}(\mathrm{mmol} / \mathrm{l})$ & $10.99 \pm 0.08$ & 149 & $12.07 \pm 0.20$ & 125 & $3.13 \times 10^{-02}$ \\
\hline Fasting insulin ${ }^{\mathrm{a}}(\mathrm{pmol} / \mathrm{l})$ & $78.17 \pm 12.67$ & 51 & $51.8 \pm 5.35$ & 125 & $3.74 \times 10^{-06}$ \\
\hline HOMA2-B ${ }^{\mathrm{a}}$ & $123.99 \pm 7.55$ & 45 & $76.61 \pm 3.83$ & 109 & $3.00 \times 10^{-09}$ \\
\hline HOMA2-IR ${ }^{\mathrm{a}}$ & $1.26 \pm 0.10$ & 45 & $1.04 \pm 0.10$ & 109 & $1.11 \times 10^{-03}$ \\
\hline
\end{tabular}

${ }^{a}$ adjusted for age and BMI

This article is protected by copyright. All rights reserved. 
Table 2. Association of T2D and GDM risk loci previously reported in the Indian population based studies with GDM risk in Indian and Sweden pregnant women. CHR $=$ chromosome, $\mathrm{BP}=$ base pair coordinates, $\mathrm{A} 1=$ effect allele, $\mathrm{n}=$ study population size, $O R=$ odds ratio $(C I=95 \%$ confidence intervals $), P=$ two-tailed $p$-value for single test.

\begin{tabular}{|c|c|c|c|c|c|c|c|c|}
\hline $\mathrm{CHR}$ & SNP & locus & $\mathrm{A} 1$ & Study & $\mathrm{n}$ & GDM_N & $\mathrm{OR}(\mathrm{Cl})$ & $P$ \\
\hline \multirow[t]{8}{*}{15} & rs7178572 & $\begin{array}{l}\text { HMG20A } \\
\text { /DUSP9 }\end{array}$ & \multirow[t]{2}{*}{$\mathrm{G} / \mathrm{A}$} & PunjabiGDM & 3346 & 122 & $1.34(1.01-1.76)$ & 0.03 \\
\hline & \multirow{7}{*}{$\begin{array}{l}\text { rs7177055 } \\
*\end{array}$} & & & Malmö-Mamma & 476 & 144 & $1.22(0.87-1.69)$ & 0.25 \\
\hline & & HMG20A & \multirow{6}{*}{$\mathrm{G} / \mathrm{A}$} & & & 8 & & \\
\hline & & /DUSPg & & Radiel & 398 & & $0.35(0.08-1.57)$ & 0.15 \\
\hline & & & & Stork & 512 & & $1.69(0.47-6.25)$ & 0.41 \\
\hline & & & & Stork-G & 268 & & $0.22(.0 .5-0.96)$ & 0.02 \\
\hline & & & & meta-analysis EU & & & & 0.60 \\
\hline & & & & meta-analysis ALL & & & & 0.15 \\
\hline \multirow[t]{3}{*}{7} & \multirow[t]{3}{*}{ rs1799999 } & \multirow[t]{3}{*}{ PPP1G.G } & \multirow[t]{3}{*}{$C / A$} & PunjabiGDM & 3664 & 124 & $1.30(0.99-1.70)$ & 0.06 \\
\hline & & & & Malmö-Mamma & 465 & 144 & $1.20(0.70-2.08)$ & 0.50 \\
\hline & & & & meta-analysis & & & & 0.04 \\
\hline \multirow[t]{2}{*}{20} & \multirow[t]{2}{*}{ rs4812829 } & \multirow[t]{2}{*}{ HNF4A } & \multirow[t]{2}{*}{$G / A$} & PunjabiGDM & 3756 & 124 & $1.16(0.87-1.57)$ & 0.30 \\
\hline & & & & $\begin{array}{c}\text { Malmö-Mamma } \\
\text { meta-analysis }\end{array}$ & & & & \\
\hline \multirow[t]{3}{*}{11} & \multirow[t]{3}{*}{ rs689 } & \multirow[t]{3}{*}{ INS } & \multirow[t]{3}{*}{$\mathrm{A} / \mathrm{T}$} & PunjabiGDM & 3676 & \multirow{3}{*}{$\begin{array}{l}122 \\
144\end{array}$} & \multirow{3}{*}{$\begin{array}{c}1.09(0.78-1.52) \\
1.101(0.80- \\
1.51)\end{array}$} & 0.60 \\
\hline & & & & Malmö-Mamma & 489 & & & 0.55 \\
\hline & & & & meta-analysis & & & & 0.49 \\
\hline \multirow{3}{*}{$\begin{array}{l}13 \\
13\end{array}$} & \multirow[t]{3}{*}{ rs9552911 } & \multirow[t]{3}{*}{ SGCG } & \multirow[t]{3}{*}{$A / G$} & PunjabiGDM & 3665 & \multirow{3}{*}{$\begin{array}{l}121 \\
144\end{array}$} & \multirow{3}{*}{$\begin{array}{c}0.85(0.54-1.32) \\
1.23(0.11- \\
13.76)\end{array}$} & 0.47 \\
\hline & & & & Malmö-Mamma & 486 & & & 0.86 \\
\hline & & & & meta-analysis & & & & 0.54 \\
\hline \multirow[t]{3}{*}{2} & \multirow[t]{3}{*}{ rs998451 } & $\begin{array}{l}\text { TMEM163, } \\
\text { RAB3GAP1 }\end{array}$ & \multirow[t]{3}{*}{$\mathrm{G} / \mathrm{A}$} & PunjabiGDM & 3656 & 122 & $1.18(0.76-1.82)$ & 0.47 \\
\hline & & & & Malmö-Mamma & 482 & 144 & $0.93(0.70-1.25)$ & 0.65 \\
\hline & & & & meta-analysis & & & & 0.16 \\
\hline
\end{tabular}

$* r^{2}$ o f 0.89 with rs 7178572

This article is protected by copyright. All rights reserved. 
Table 3. Association of previously reported GDM risk loci discovered in the European population based studies with GDM risk in Indian and Sweden pregnant women. CHR $=$ chromosome, $B P=$ base pair coordinates, $A 1=$ effect allele, $\mathrm{n}=$ study population size, $O R=$ odds ratio, $P=$ two-tailed $p$-value for single test.

\begin{tabular}{|c|c|c|c|c|c|c|c|c|}
\hline $\begin{array}{c}\mathrm{CH} \\
\mathrm{R}\end{array}$ & SNP & Locus & $\begin{array}{l}\text { RA/ } \\
\text { OA }\end{array}$ & Study & $\mathbf{n}$ & GDM_N & OR (CI) & $\mathbf{P}$ \\
\hline \multirow[t]{7}{*}{4} & rs10010131 & WFS1 & $\mathrm{G} / \mathrm{A}$ & PunjabiGDM & 3617 & 121 & $1.24(0.92-1.66)$ & 0.15 \\
\hline & & & & Malmö-Mamma & 444 & 144 & $1,19(0.88-1.64)$ & 0.25 \\
\hline & & & & Radiel & - & 8 & - & - \\
\hline & & & & Stork & 512 & 8 & $2.38(0.75-7.69)$ & 0.13 \\
\hline & & & & Stork-G & 268 & & $2.17(0.43-11.11)$ & 0.32 \\
\hline & & & & meta-analysis_EU & & & & 0.45 \\
\hline & & & & meta-analysis_ALL & & & & 0.10 \\
\hline \multirow[t]{7}{*}{9} & rs10811661 & $C D K N 2 B$ & $\mathrm{~T} / \mathrm{C}$ & PunjabiGDM & 3666 & 122 & $0.99(0.68-1.44)$ & 0.96 \\
\hline & & & & Malmö-Mamma & 428 & 144 & $1.31(0.81-2.12)$ & 0.25 \\
\hline & & & & Radiel & 398 & 8 & $0.66(0.18-2.38)$ & 0.53 \\
\hline & & & & Stork & 512 & 8 & $1.56(0.34-7.14)$ & 0.56 \\
\hline & & & & Stork-G & - & 4 & - & - \\
\hline & & & & meta-analysis_EU & & & & 0.93 \\
\hline & & & & meta-analysis_ALL & & & & 0.99 \\
\hline \multirow[t]{7}{*}{10} & rs1111875 & $\begin{array}{c}\text { HHEX / } \\
I D E\end{array}$ & $\mathrm{G} / \mathrm{A}$ & PunjabiGDM & 3675 & 120 & $1.02(0.79-1.33)$ & 0.86 \\
\hline & & & & Malmö-Mamma & 443 & 144 & $1.41(1.03-1.92)$ & 0.031 \\
\hline & & & & Radiel & 398 & 8 & $3.03(0.84-11.11)$ & 0.075 \\
\hline & & & & Stork & 512 & 8 & $0.69(0.25-1.85)$ & 0.45 \\
\hline & & & & Stork-G & 268 & 4 & $1.33(0.31-5.88)$ & 0.70 \\
\hline & & & & meta-analysis_EU & & & & 0.08 \\
\hline & & & & meta-analysis_ALL & & & & 0.26 \\
\hline \multirow[t]{7}{*}{3} & rs11708067 & $A D C Y 5$ & $A / G$ & PunjabiGDM & 3648 & 123 & $0.78(0.58-1.04)$ & 0.084 \\
\hline & & & & Malmö-Mamma & 466 & 144 & $1.44(1.00-2.08)$ & 0.054 \\
\hline & & & & Radiel & 398 & 8 & $0.95(0.36-3.33)$ & 0.94 \\
\hline & & & & Stork & 512 & 8 & $0.46(0.16-1.31)$ & 0.13 \\
\hline & & & & Stork-G & 268 & 4 & $0.87(0.17-4.54)$ & 0.86 \\
\hline & & & & meta-analysis_EU & & & & 0.93 \\
\hline & & & & meta-analysis_ALL & & & & 0.16 \\
\hline \multirow[t]{7}{*}{8} & rs13266634 & SLC30A8 & $\mathrm{T} / \mathrm{C}$ & PunjabiGDM & 3671 & 122 & $0.97(0.72-1.31)$ & 0.84 \\
\hline & & & & Malmö-Mamma & 458 & 144 & $0.88(0.64-1.20)$ & 0.42 \\
\hline & & & & Radiel & 398 & 8 & $1.36(0.50-3.69)$ & 0.54 \\
\hline & & & & Stork & & & & \\
\hline & & & & Stork-G & & & & \\
\hline & & & & meta-analysis_EU & & & & 0.86 \\
\hline & & & & meta-analysis_ALL & & & & 0.78 \\
\hline
\end{tabular}

This article is protected by copyright. All rights reserved. 


\begin{tabular}{|c|c|c|c|c|c|c|c|c|}
\hline \multirow[t]{7}{*}{3} & rs1801282 & PPARG & $C / G$ & PunjabiGDM & 3436 & 116 & $1.06(0.71-1.58)$ & 0.76 \\
\hline & & & & Malmö-Mamma & 421 & 144 & $0.75(0.48-1.16)$ & 0.21 \\
\hline & & & & Radiel & & & & \\
\hline & & & & Stork & & & & \\
\hline & & & & Stork-G & & & & \\
\hline & & & & meta-analysis_EU & & & & 0.21 \\
\hline & & & & meta-analysis_ALL & & & & 0.89 \\
\hline \multirow[t]{7}{*}{9} & rs2796441 & TLE1 & $\mathrm{C} / \mathrm{T}$ & PunjabiGDM & 3677 & 122 & $0.98(0.75-1.27)$ & 0.88 \\
\hline & & & & Malmö-Mamma & 457 & 144 & $1.00(0.33-2.94)$ & 0.98 \\
\hline & & & & Radiel & 398 & 8 & $0.64(0.24-1.72)$ & 0.38 \\
\hline & & & & Stork & 512 & 8 & $1.44(0.53-3.86)$ & 0.46 \\
\hline & & & & Stork-G & 268 & 4 & $0.48(0.09-2.38)$ & 0.35 \\
\hline & & & & meta-analysis_EU & & & & 0.63 \\
\hline & & & & meta-analysis_ALL & & & & 0.69 \\
\hline \multirow[t]{7}{*}{3} & rs4402960 & IGF2BP2 & $\mathrm{T} / \mathrm{G}$ & PunjabiGDM & 3535 & 121 & $0.89(0.69-1.15)$ & 0.36 \\
\hline & & & & Malmö-Mamma & 352 & 144 & $1.06(0.73-1.53)$ & 0.77 \\
\hline & & & & Radiel & & & & \\
\hline & & & & Stork & 512 & 8 & $1.48(0.53-4.13)$ & 0.44 \\
\hline & & & & Stork-G & 268 & 4 & $0.73(0.14-3.70)$ & 0.71 \\
\hline & & & & meta-analysis_EU & & & & 0.62 \\
\hline & & & & meta-analysis_ALL & & & & 0.59 \\
\hline \multirow[t]{7}{*}{11} & rs5219 & KCNJ11 & $\mathrm{T} / \mathrm{C}$ & PunjabiGDM & 3382 & 117 & $1.04(0.80-1.36)$ & 0.73 \\
\hline & & & & Malmö-Mamma & 264 & 144 & 1.09 (0.70 -1.67) & 0.71 \\
\hline & & & & Radiel & 398 & 8 & $1.43(0.53-3.89)$ & 0,47 \\
\hline & & & & Stork & & & & \\
\hline & & & & Stork-G & & & & \\
\hline & & & & meta-analysis_EU & & & & 0.43 \\
\hline & & & & meta-analysis_ALL & & & & 0.53 \\
\hline \multirow[t]{7}{*}{2} & rs560887 & G6PC2 & $\mathrm{G} / \mathrm{A}$ & PunjabiGDM & 3678 & 122 & $0.93(0.64-1.35)$ & 0.70 \\
\hline & & & & Malmö-Mamma & 383 & 144 & $1.25(0.85-1.81)$ & 0.26 \\
\hline & & & & Radiel & 398 & 8 & $0.90(0.30-2.63)$ & 0,85 \\
\hline & & & & Stork & 512 & 8 & $0.96(0.33-2.80)$ & 0.94 \\
\hline & & & & Stork-G & 268 & 4 & $0.36(0.04-2.97)$ & 0.32 \\
\hline & & & & meta-analysis_EU & & & & 0.36 \\
\hline & & & & meta-analysis_ALL & & & & 0.86 \\
\hline \multirow[t]{5}{*}{6} & rs7754840 & CDKAL1 & $C / G$ & PunjabiGDM & 3502 & 116 & $1.19(0.90-1.57)$ & 0.22 \\
\hline & & & & Malmö-Mamma & 426 & 144 & $0.97(0.71-1.32)$ & 0.83 \\
\hline & & & & Radiel & 398 & 8 & $1.42(0.52-3.84)$ & 0,49 \\
\hline & & & & Stork & 512 & 8 & $0.96(0.33-2.79)$ & 0.93 \\
\hline & & & & Stork-G & 268 & 4 & $0.70(0.14-3.51)$ & 0.66 \\
\hline
\end{tabular}

This article is protected by copyright. All rights reserved. 


\begin{tabular}{|c|c|c|c|c|c|c|c|c|}
\hline & & & & $\begin{array}{l}\text { meta-analysis_EU } \\
\text { meta-analysis_ALL }\end{array}$ & & & & $\begin{array}{l}0.99 \\
0.31\end{array}$ \\
\hline \multirow[t]{7}{*}{6} & rs7756992 & $C D K A L 1$ & $\mathrm{G} / \mathrm{A}$ & PunjabiGDM & 3469 & 115 & $1.16(0.88-1.55)$ & 0.29 \\
\hline & & & & Malmö-Mamma & 425 & 144 & $0.96(0.70-1.32)$ & 0.79 \\
\hline & & & & Radiel & & & & \\
\hline & & & & Stork & 512 & 8 & $0.85(0.27-2.79)$ & 0.77 \\
\hline & & & & Stork-G & 268 & 4 & $0.81(0.17-4.32)$ & 0.85 \\
\hline & & & & meta-analysis_EU & & & & 0.65 \\
\hline & & & & meta-analysis_ALL & & & & 0.50 \\
\hline \multirow[t]{7}{*}{10} & rs7903146 & TCF7L2 & $\mathrm{T} / \mathrm{C}$ & PunjabiGDM & 3330 & 108 & $1.29(0.98-1.72)$ & 0.07 \\
\hline & & & & Malmö-Mamma & 373 & 144 & $1.20(0.84-1.70)$ & 0.31 \\
\hline & rs12255372 & & & Radiel & 398 & 8 & $0.28(0.04-2.15)$ & 0,193 \\
\hline & & & & Stork & 512 & 8 & $0.63(0.18-2.24)$ & 0.47 \\
\hline & & & & Stork-G & 268 & 4 & $0.86(0.17-4.32)$ & 0.85 \\
\hline & & & & meta-analysis_EU & & & & 0.51 \\
\hline & & & & meta-analysis_ALL & & & & 0.27 \\
\hline \multirow[t]{7}{*}{16} & rs9939609 & FTO & $\mathrm{A} / \mathrm{T}$ & PunjabiGDM & 2962 & 88 & $0.79(0.57-1.10)$ & 0.16 \\
\hline & & & & Malmö-Mamma & 0 & & NA & NA \\
\hline & & & & Radiel & & & & \\
\hline & & & & Stork & & & & \\
\hline & & & & Stork-G & & & & \\
\hline & & & & meta-analysis_EU & & & & \\
\hline & & & & meta-analysis_ALL & & & & \\
\hline \multirow[t]{7}{*}{11} & rs10830963 & MTNR1B & $\mathrm{G} / \mathrm{C}$ & PunjabiGDM & 3495 & 114 & $0.93(0.72-1.23)$ & 0.65 \\
\hline & & & & Malmö-Mamma & 425 & 144 & $1.03(0.75-1.41)$ & 0.85 \\
\hline & & & & Radiel & 398 & 8 & $2.85(0.95-8.6)$ & 0.052 \\
\hline & & & & Stork & 512 & 8 & $0.88(0.28-2.76)$ & 0.83 \\
\hline & & & & Stork-G & 268 & 4 & $0.92(0.18-4.63)$ & 0.92 \\
\hline & & & & meta-analysis_EU & & & & 0.37 \\
\hline & & & & meta-analysis_ALL & & & & 0.89 \\
\hline
\end{tabular}

This article is protected by copyright. All rights reserved. 
Table 4. Association of previously reported T2D risk loci discovered in the European population based studies with GDM risk in Indian and Sweden pregnant women. CHR $=$ chromosome, $B P=$ base pair coordinates, $A 1=$ effect allele, $\mathbf{n}=$ study population size, $\mathrm{OR}=$ odds ratio, $P=$ two-tailed $p$-value for single test.

\begin{tabular}{|c|c|c|c|c|c|c|c|c|}
\hline CHR & SNP & Locus & $\begin{array}{c}\text { RA/ } \\
\text { OA }\end{array}$ & Study & $\mathbf{n}$ & GDM_N & OR (CI) & $\mathbf{P}$ \\
\hline \multirow[t]{7}{*}{10} & rs12571751 & ZMIZ1 & $A / G$ & PunjabiGDM & 3390 & 117 & $0.80(0.62-1.05)$ & 0.11 \\
\hline & & & & Malmö-Mamma & 492 & 144 & $0.72(0.54-0.95)$ & 0.021 \\
\hline & & & & Radiel & 398 & 8 & $1.68(0.61-4.68)$ & 0.31 \\
\hline & & & & Stork & 512 & 8 & $0.95(0.36-2.56)$ & 0.92 \\
\hline & & & & Stork-G & 268 & 4 & $0.30(0.06-1.50)$ & 0.11 \\
\hline & & & & meta-analysis EU & & & & 0.15 \\
\hline & & & & meta-analysis ALL & & & & 0.03 \\
\hline \multirow[t]{7}{*}{11} & rs11605924 & CRY2 & $A / C$ & PunjabiGDM & 3679 & 120 & $0.67(0.52-0.87)$ & 0.002 \\
\hline & & & & Malmö-Mamma & 484 & 144 & $1.44(1.08-1.91)$ & $\begin{array}{c}0.012 \\
9\end{array}$ \\
\hline & & & & Radiel & 398 & 8 & $1.39(0.50-3.85)$ & 0.53 \\
\hline & & & & Stork & 512 & 8 & $1.62(0.58-4.94)$ & 0.35 \\
\hline & & & & Stork-G & 268 & 4 & $1.69(0.40-7.15)$ & 0.46 \\
\hline & & & & meta-analysis EU & & & & 0.014 \\
\hline & & & & meta-analysis ALL & & & & 0.26 \\
\hline \multirow[t]{7}{*}{11} & rs2237895 & KCNQ1 & $\mathrm{C} / \mathrm{A}$ & PunjabiGDM & 3463 & 113 & $0.81(0.62-1.06)$ & 0.13 \\
\hline & & & & Malmö-Mamma & 410 & 144 & $1.43(1.06-1.94)$ & $\begin{array}{c}0.020 \\
4\end{array}$ \\
\hline & & & & Radiel & 398 & 8 & $1.20(0.44-3.23)$ & 0.72 \\
\hline & & & & Stork & 512 & 8 & $1.15(0.43-3.10)$ & 0.77 \\
\hline & & & & Stork-G & 268 & 4 & $0.41(0.08-2.06)$ & 0.26 \\
\hline & & & & meta-analysis EU & & & & 0.29 \\
\hline & & & & meta-analysis ALL & & & & 0.51 \\
\hline \multirow[t]{7}{*}{15} & rs7177055 & HMG20A & $A / G$ & PunjabiGDM & 3680 & 122 & $1.35(1.03-1.75)$ & 0.024 \\
\hline & & & & Malmö-Mamma & 457 & 144 & $1.09(0.79-1.52)$ & 0.58 \\
\hline & & & & Radiel & & & & \\
\hline & & & & Stork & 512 & 8 & $1.65(0.47-5.83)$ & 0.43 \\
\hline & & & & Stork-G & 268 & 4 & $0.21(0.05-0.91)$ & 0.02 \\
\hline & & & & meta-analysis EU & & & & 0.82 \\
\hline & & & & meta-analysis ALL & & & & 0.06 \\
\hline \multirow[t]{7}{*}{18} & rs8090011 & LAMA1 & G/C & PunjabiGDM & 3683 & 122 & $1.02(0.79-1.32)$ & 0.89 \\
\hline & & & & Malmö-Mamma & 457 & 144 & $1.49(1.11-2.01)$ & 0.009 \\
\hline & & & & Radiel & & & & \\
\hline & & & & Stork & & & & \\
\hline & & & & Stork-G & & & & \\
\hline & & & & meta-analysis EU & & & & \\
\hline & & & & meta-analysis ALL & & & & 0.31 \\
\hline
\end{tabular}

This article is protected by copyright. All rights reserved. 


\begin{tabular}{|c|c|c|c|c|c|c|c|c|}
\hline \multirow[t]{7}{*}{23} & rs5945326 & DUSP9 & $A / G$ & PunjabiGDM & 3377 & 113 & $0.87(0.66-1.13)$ & 0.29 \\
\hline & & & & Malmö-Mamma & 495 & 144 & $1.44(1.03-2.05)$ & 0.035 \\
\hline & & & & Radiel & & & & \\
\hline & & & & Stork & 512 & 8 & $0.40(0.15-1.08)$ & 0.06 \\
\hline & & & & Stork-G & 268 & 4 & $2.31(0.28-18.95)$ & 0.42 \\
\hline & & & & meta-analysis EU & & & & 0.62 \\
\hline & & & & meta-analysis ALL & & & & 0.52 \\
\hline
\end{tabular}

This article is protected by copyright. All rights reserved. 
Table 5. GDM Genetic risk scores for Punjabi GDM and Malmö Mamma studies based on (1) all previously reported GDM SNPs, (2) GDM loci reported in Indian populations, (3) previously reported T2D loci, (4) T2D loci from studies on Indian population, (5) all T2D and GDM loci and (6) T2D and GDM reported on Indian populations. All SNPs for GRS are reported in supplementary table 1.

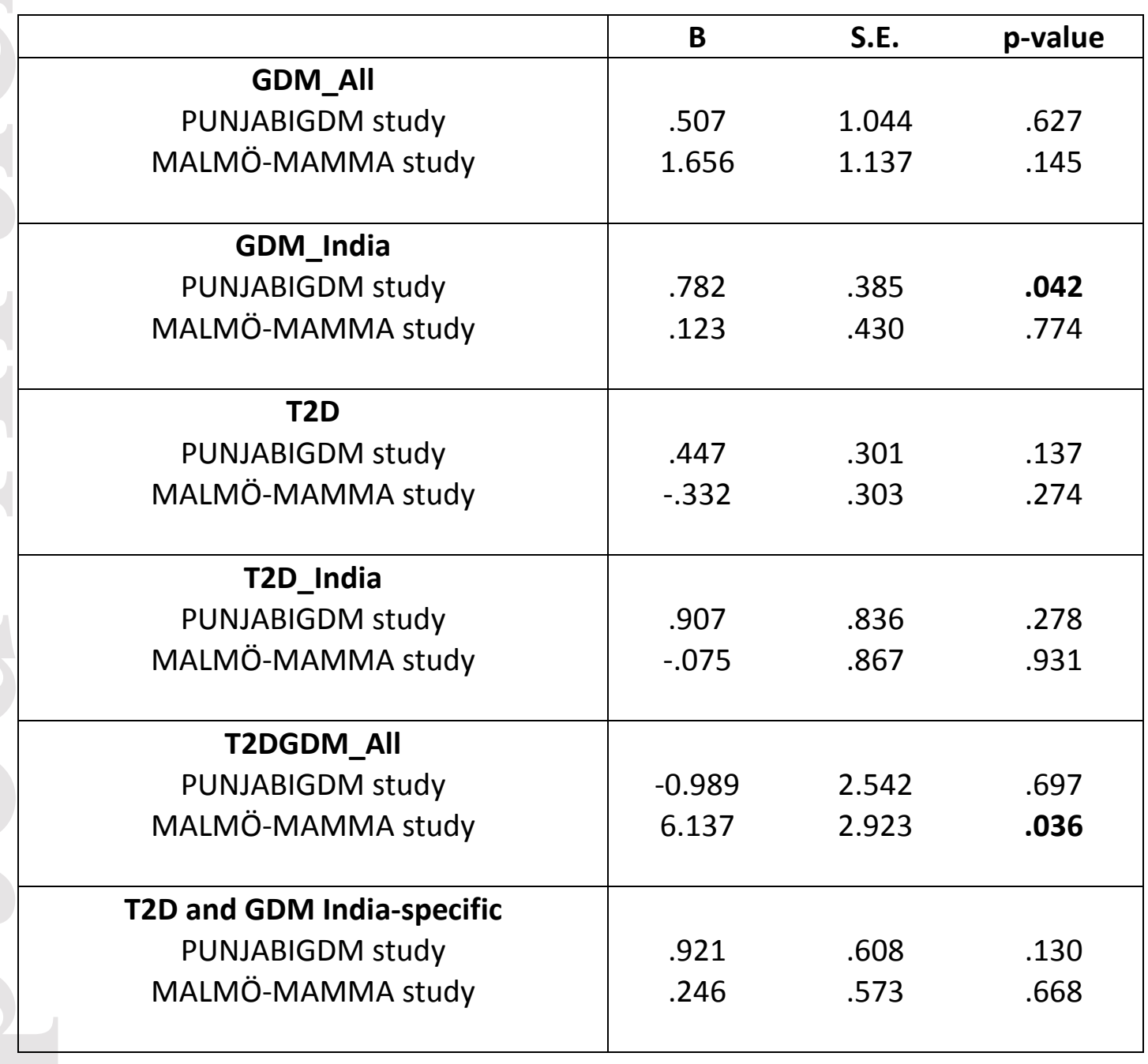

This article is protected by copyright. All rights reserved. 
Figures

A

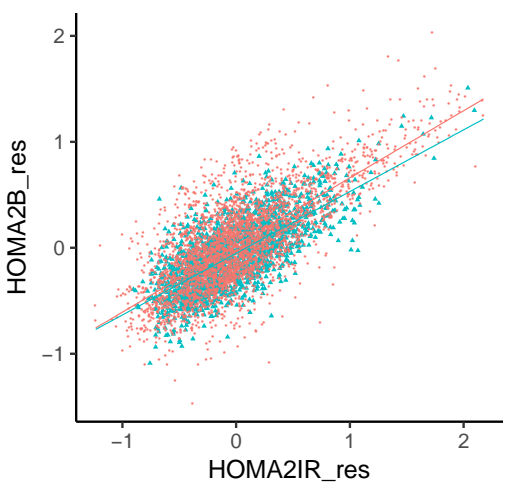
cohort

- IND

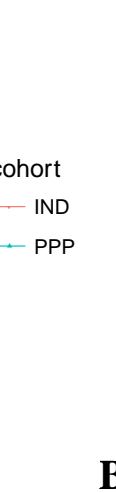

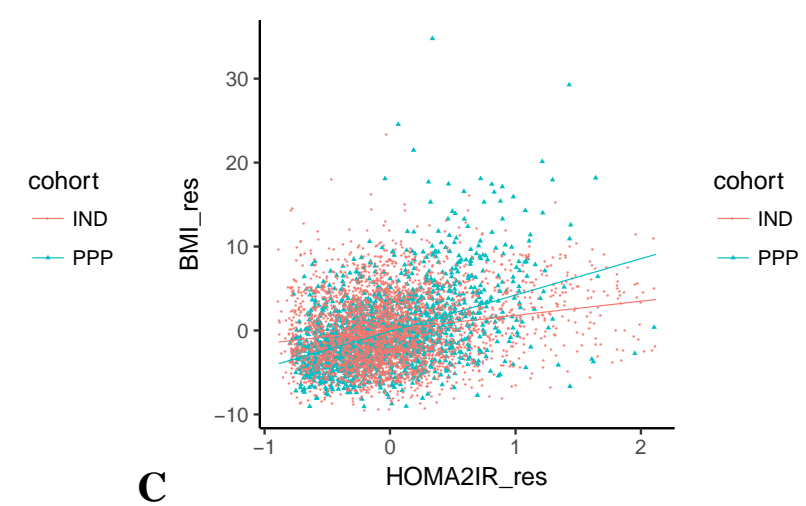

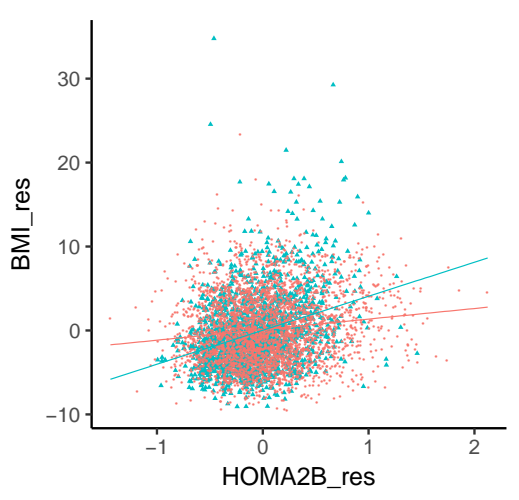

PPP bet

Compare

a

BMI_res HOMA2B_res

BMI_res HOMA2IR_res

HOMA2B res $\sim$ HOMA2IR res

4.055

4.339

0.582

\section{IND_beta}

PPP_se

IND_se

pvalue

\begin{tabular}{|c|c|c|c|c|}
\hline 1.260 & 0.292 & 0.165 & 8.324 & $8.486 \mathrm{e}-17$ \\
\hline 1.686 & 0.216 & 0.141 & 10.286 & $8.112 \mathrm{e}-25$ \\
\hline 0.634 & 0.014 & 0.010 & -2.989 & 0.0028 \\
\hline
\end{tabular}

Figure 1. Relationship between (A) HOMA2-B-HOMA2-IR (B) HOMA2-B and BMI and (C) HOMA2-IR and BMI in Indian and Scandinavian women from the Botnia-PPP study with normal glucose tolerance (NGT). ). $\mathrm{Z}=\mathrm{z}$ scores for the differences between effects in Indian and Swedish women.

This article is protected by copyright. All rights reserved. 


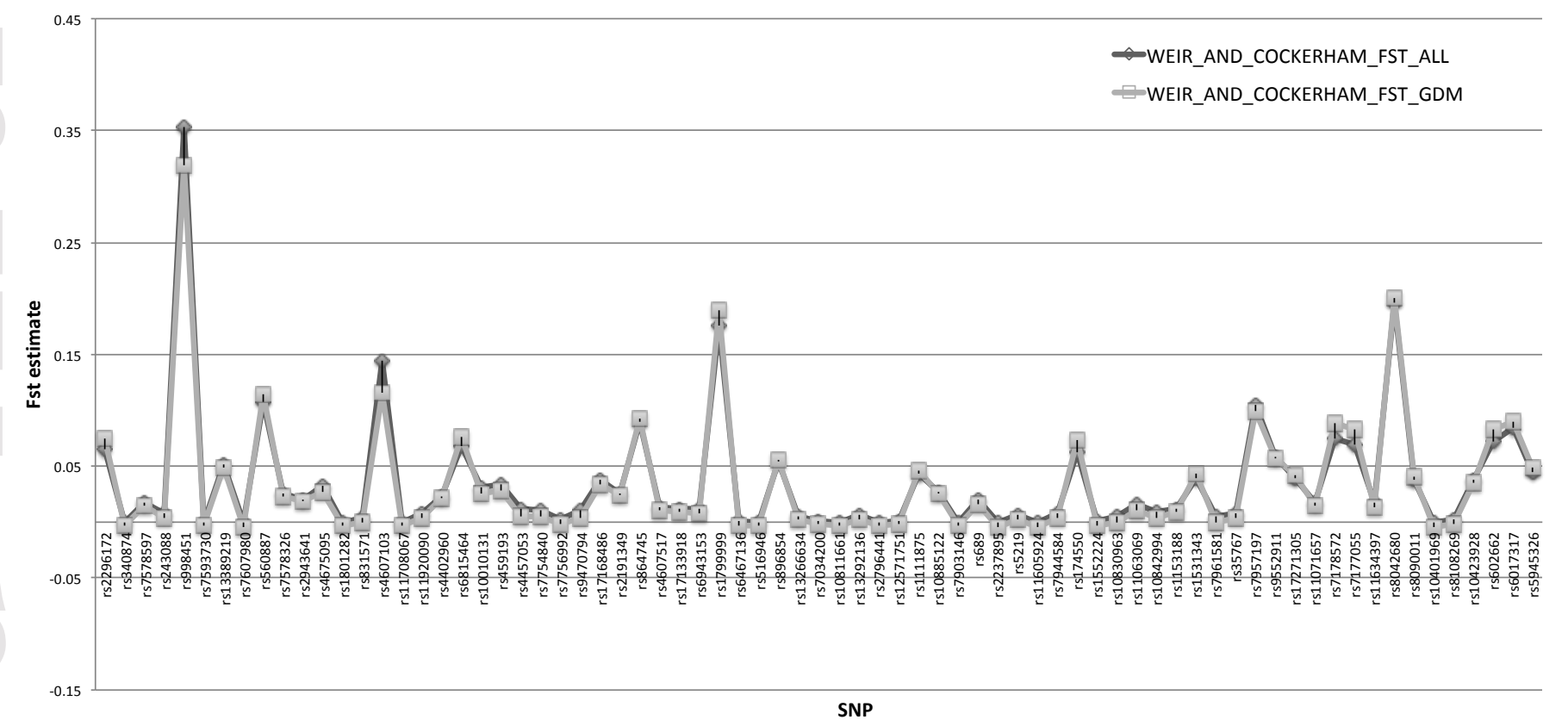

Figure 1. F F $_{\text {ST }}$ estimates for all (in grey) and GDM (in black). Great differentiation was observed at TMEM163 PRC1 and PPP1R3A whereas moderate at ADAMTS8, G6PC2, OASL, JAZF1, HNF4A, HMG20A, MAEA MACF1, FADS1, SGCG, TP53INP1, and GRB14 loci. 